\title{
The role of nonzero conjectural variation in pollution abatement and output in the design of emission taxes
}

\author{
Luis Gautier (D) \\ Department of Social Sciences, University of Texas at Tyler, 3900 University Blvd., Tyler, TX 75799, USA \\ Corresponding author. lgautier@uttyler.edu
}

(Submitted 21 March 2018; revised 20 March 2019, 17 September 2019, 18 August 2020, 07 January 2021; accepted 16 March 2021; first published online 1 June 2021)

\begin{abstract}
The presence of nonzero conjectural variations in pollution abatement and output make emission taxes less effective with respect to reducing emissions. This has implications for the characterization of the optimal emission tax, particularly in an international context where there are large asymmetries in pollution intensities. A higher degree of collusion in output between polluting firms results in higher emissions taxes in the non-cooperative equilibrium. In contrast, a higher degree of collusion in abatement between polluting firms results in lower emissions taxes in the non-cooperative equilibrium. These results rely on the presence of nonzero conjectural variations and large asymmetries in pollution intensities across countries. The analysis is relevant to the design of international environmental policy, including cases where countries face increasing global competition and damages from rising global emissions.
\end{abstract}

Keywords: emission tax; international environmental agreements; nonzero conjectural variation; pollution intensities

JEL classification: H23; L13; Q5

\section{Introduction}

In the context of international environmental agreements, countries with varying degrees of pollution intensities who are engaging in negotiations are likely to account for potential losses in cost competitiveness as well as issues of carbon leakage in the design of policy (e.g., Finus, 2003; Gautier, 2017; Lahiri and Symeonidis, 2017). In addition, competing firms operating within these countries make assumptions about firm interdependence (i.e., conjectural variations) with implications, in turn, on the design of policy.

This paper develops a two-country model where firms form conjectures about their competitors' output and abatement. The implications of the presence of these conjectures on the characterization of the optimal emission tax, and how effective the tax is terms of the Creative Commons Attribution-NonCommercial-ShareAlike licence (http://creativecommons.org/licenses/ by-nc-sa/4.0), which permits non-commercial re-use, distribution, and reproduction in any medium, provided the same Creative Commons licence is used to distribute the re-used or adapted article and the original article is properly cited. The written permission of Cambridge University Press must be obtained prior to any commercial use. 
in affecting output and emissions, are examined. It is shown inter alia that a higher degree of collusion in output between polluting firms results in higher emissions taxes in the non-cooperative equilibrium, while a higher degree of collusion in abatement between polluting firms results in lower emissions taxes in the non-cooperative equilibrium. These results depend crucially on the presence of nonzero conjectural variations and large asymmetries in pollution intensities. The notion of nonzero conjectural variation is captured by assuming that firm 1, say, believes that its own output is tied to firm 2 's output via the conjectural variation relation. In other words, firm 1 makes a conjecture about firm 2's reaction to a change in the output of firm 1 (Figuières et al., 2004). An analogous analytical framework is applied to the notion of conjectural variation in abatement.

A large number of papers in the literature on environmental policy under oligopoly assume zero conjectural variations (e.g., Levin, 1985; Simpson, 1995; Ulph, 1996; Lee, 1999; Requate, 2006; Ulph and Ulph, 2007; Fujiwara, 2009; Lambertini, 2013), but at the same time there are good reasons to believe that this assumption may not be consistent with concerns put forward by countries engaging in international environmental agreements. For example, Gelves and McGinty (2016: 67) argue that the presence of carbon leakage is an acknowledgement that countries respond to other countries' decisions on emissions and output, a scenario assumed away under zero conjectures. Moreover, the literature which explores the role of conjectural variations has assumed mainly nonzero conjectural variations in either pollution abatement (e.g., Lee and Kim, 1995; Gelves and McGinty, 2016) or output (e.g., Ebert, 1992). Kim and Chang (1993), in contrast, assume nonzero conjectural variation in abatement and output, but do not look at the role of nonzero conjectural variation in an international context and does not trace the degree of nonzero conjectural variations with respect to optimal policy (due to the generality of the model specification), two aspects which we examine. By degree of conjectural variation we mean a continuum between the extreme cases of perfect competition and collusion. This notion is formally defined in section 2 .

A key contribution of this paper is thus the treatment of nonzero conjectural variations in output and abatement. The main insight from having a unified framework is that it allows us to explore cases that would not be possible otherwise. For example, collusion in the output market suggests that industry output would be lower, a case normally associated with higher prices. In the case of collusion, industry output is lower because firms restrict output and thus charge a higher price to obtain higher profits. However, in the presence of conjectural variation in abatement, industry output could be higher because collusion in abatement may entail higher emissions and therefore a higher associated output level. The reason higher emissions may arise is because firms seek to lower abatement costs by polluting more. These changes in abatement and output have, in turn, implications for the design of policy.

Moreover, the presence of both conjectures (not just one) undermines the effectiveness of an increase in the emission tax in reducing emissions. Specifically, we show (proposition 5.4) that in the presence of large asymmetries in pollution intensities, the effectiveness of an increase in the emission tax in reducing emissions is lower if conjectural variation in abatement is close to collusion or in the case where conjectural variation in output is close to perfect competition. The reason for the former is that with a relatively higher degree of collusion in abatement (e.g., more pollution takes place) marginal abatement costs increase, thereby making a tax increase less effective in lowering emissions. This reduced effectiveness of the tax arises in the analysis via higher 
marginal abatement costs, since now firm 1, say, incorporates into its abatement cost structure the emissions coming from firm 2, i.e., conjectural variation relation. In the case of the latter where the output market is close to perfect competition, higher taxation on relatively less pollution-intensive firms implies relatively large increases in the output of the relatively more pollution-intensive firm (both because demand is more price sensitive and because of the presence of the oligopolistic interaction of firms) and thus aggregate emissions.

Overall, the literature has looked at the extreme cases of nonzero conjectural variations (i.e., perfect competition on the one hand and collusion on the other), but here we look at intermediate cases which allow us to trace the characterization of policy for a range of cases. The insight obtained from considering intermediate cases is at least threefold. First, we argue, for example, that a relatively higher degree of conjectural variation makes emission taxes less effective with respect to reducing emissions; it would not be possible to explore such a scenario in a framework which considers only extreme cases. Second, some results can be generalized, meaning that they do not depend on conditions inherent in the extreme cases. Third, we show that some results do not depend on conjectural variations, which helps rule out the role of conjectural variations when making policy recommendations.

This paper does not touch on aspects of consistent conjectures. Our contribution is to capture potential relationships in abatement and output across competing firms without the restrictions inherent in the behavioral assumptions under consistent conjectural variations, where the slopes of the reaction functions are equal to conjectural variations. ${ }^{1}$ In this paper we derive bounds for conjectural variations based on firms' profit maximizing conditions, while allowing for a flexible range of potential relationships (i.e., conjectural variations) seen in an international context. The derivation of these bounds minimizes the degree of arbitrariness associated with the definition of conjectural variations.

A third important contribution of the paper is the treatment of nonzero conjectural variations in abatement and output, along with the dimension of asymmetry in pollution intensities. This dimension seeks to capture existing differences in pollution intensities. The paper also presents closed-form solutions which enable us to trace a myriad of cases which capture the relationship between conjectural variations and policy, an aspect new to the literature.

The analysis indicates that the presence of large asymmetries in pollution intensities plays an important role in explaining the extent to which the tax is effective in reducing aggregate emissions (section 5). We show that, due to the presence of large asymmetries in pollution intensities, aggregate emissions may fall with lower taxation. This is because although lower taxation on the relatively low-polluting firm renders that firm relatively more cost competitive thereby raising emissions by that firm, this is completely offset by the reduction in output and thus emissions by the relatively high-polluting and less costcompetitive firm. Even though this type of effect has been discussed in the literature (e.g., Gautier, 2019), here we look at the interplay between asymmetries in pollution intensities and the degree of conjectural variation.

\footnotetext{
${ }^{1}$ See Bresnahan (1981) for a discussion on the concept of consistent conjectures. The use of consistent conjectures has been criticized in the literature because it imposes behavioral restrictions by setting an arbritrary dynamic process, but the literature has studied issues of international trade (e.g., Fung, 1989) and international environmental agreements (e.g., Gelves and McGinty, 2016) using consistent conjectures.
} 
The presence of large enough asymmetries in pollution intensities and nonzero conjectural variations also plays a crucial role in the design of the emission tax (section 6). The analysis indicates that output markets characterized by a relatively high degree of collusion will result in a higher emission tax in the non-cooperative equilibrium relative to the zero (Cournot-Nash) conjectural variation rule (proposition 6.2). This is because, in the presence of large enough asymmetry in pollution intensities, the reduction in damages from the low-polluting firm becomes negligible (and thus the need to decrease taxation) relative to the gains from lower transboundary pollution/damages from the high-polluting firm. This case points to higher taxation even in markets where there is a relatively higher degree of collusion and thus a larger output distortion.

In contrast, markets with a relatively higher degree of collusion in abatement (which may lead to higher emissions) and, at the same time, sufficient asymmetry in pollution intensities, result in a lower emission tax in the non-cooperative equilibrium (proposition 6.3). The driver is that, with large asymmetries in pollution intensities, lower taxation controls aggregate emissions. This result is relevant because it shows that taxation can be lessened even in the case where countries pollute more as a result of a relatively higher degree of collusion in abatement.

The aforementioned results present new channels (i.e., the presence of nonzero conjectural variations along with large asymmetries in pollution intensities) to explain why taxation may be higher with a relatively high output distortion; and at the same time why taxation may be lower even when firms pollute more. These results contribute to the understanding of environmental policy design in an international context (see section 7 for a discussion of policy implications). Specifically, conditions are derived such that lower/higher taxation in the low pollution-intensive country may address concerns about carbon leakage and competitiveness, while at the same time help to tackle global emissions.

To achieve these objectives, section 2 develops a model of oligopolistic interdependence and nonzero conjectural variation in pollution abatement and output. The model captures the interplay between nonzero conjectural variations and asymmetries in pollution intensities. Section 3 characterizes the equilibrium by deriving closed-form solutions to trace the role of nonzero conjectural variations for a myriad of cases. Sections 4 and 5 present the comparative statics effects of changes in the conjectural variation parameters. The strategy is to examine the extent to which output and emissions rise/fall in markets where there is a relatively higher degree of collusion in abatement/output. Results are then used to examine whether an increase in the emission tax likely reduces emissions. In section 6 we characterize the optimal non-cooperative emission tax and examine the effects of changes in the conjectural variation parameter. Section 7 concludes with a discussion of policy implications.

\section{The model}

Consider a two-country model where there is one firm operating in each country, and each firm generates pollution which creates external costs to society. Firms compete in an oligopolistic industry. The firm operating in the home (foreign) country produces quantity $q^{h}\left(q^{f}\right)$, and faces linear demand $p^{k}=\alpha-\beta\left(q^{h}+q^{f}\right)$, for country $k=h, f$. Costs are given by a function $C^{k}\left(q^{k}, e^{k}, e^{-k}\right)$, where $e^{k}$ denotes net emissions (i.e., emissions after abatement) coming from the firm operating in country $k$ and $e^{-k}$ net emissions from the other firm. The properties of the cost function are given below. Each firm pays 
emission taxes $e^{k} t^{k}$ where $t^{k}$ is a per-unit emission tax. Therefore, the profit function for each firm in country $k=h, f$ is given by

$$
\pi^{k}=p^{k} q^{k}-C^{k}\left(q^{k}, e^{k}, e^{-k}\right)-e^{k} t^{k} .
$$

To capture aspects of conjectural variation in the output market, we follow Dixit (1986) where the partial derivative of $\pi^{h}$ with respect to $q^{h}$ incorporates $d q^{f} / d q^{h}$. That is, the firm in the home country is assumed to believe that its own output, $q^{h}$, is tied to the foreign firm's output $q^{f}$ via the conjectural variation relation. In other words, the home firm conjectures about the foreign firm's reaction to a change in the output of the home firm (Figuières et al., 2004). We assume that conjectural variations in output are constant and identical across firms, $d q^{f} / d q^{h}=d q^{h} / d q^{f}=v_{q}$, where $v_{q}$ is a constant between -1 and 1 . The case of collusion is captured by $v_{q} \simeq 1$, the case of perfect competition by $v_{q} \simeq-1$, and in the case of Cournot, $v_{q}=0$, since firms take each other's output as given (Ebert, 1992). The reason for assuming $v_{q}$ constant is to facilitate the analysis of the individual (separate) role of conjectural variations in abatement and output.

In addition to conjectural variation in output, we incorporate conjectural variation in abatement. Analogous to the case of the output market, the idea here is that net emissions by, say, the home firm, $e^{h}$, are tied to net emissions coming from the foreign firm, $e^{f}$. For example, the home firm may conjecture that the foreign firm pollutes more resulting from more pollution by the home firm. Alternatively, the home firm may conjecture that the foreign firm pollutes less if the home firm pollutes more. This set-up allows the analysis of zero vis-à-vis nonzero conjectural variations in abatement and output, and the study of the implications for policy design in a unified framework of analysis.

With these points in mind, we consider the following cost function for the home firm (an analogous cost function applies to the foreign firm):

$$
C^{h}\left(q^{h}, e^{h}, e^{f}\right)=c^{h} q^{h}+\left(\delta^{h} q^{h}-e^{h}-e^{f}\right)^{2} / 2,
$$

where (subscripts denote partial derivatives) $C_{q^{h}}^{h}>0, C_{q^{h} q^{h}}^{h}>0, C_{e^{h}}^{h}<0, C_{e^{h} e^{h}}^{h}>0$, $C_{q^{h} e^{h}}^{h}<0$, and $\delta^{h} q^{h}$ denotes gross pollution where $\delta^{h}$ is the pollution intensity of the home firm which is assumed constant. In (2) the first term represents production costs with constant marginal cost, $c^{h}$, and the second term abatement costs. The third term within the abatement cost component captures the extent to which foreign net emissions affect the home firm's abatement costs and net emissions. Examples include the impact on tourism and fishing industry in the Salton Sea area (Hulbert, 2008), and the impact of acid rain on local and regional agricultural yields and quality, and surface water (e.g., Menz and Seip, 2004; Fang et al., 2013; Zhang et al., 2013). The idea is that an increase (decrease) in net emissions by the foreign firm lowers (raises) abatement costs of the home firm. This is because home takes into account foreign net emissions in its cost structure. For instance, in the case of water pollution it may be relatively less costly to remove solid waste, but additional investment may be needed to remove contaminants coming from pharmaceuticals (International Joint Commission Newsletter, 2013).

The last term in (2) incorporates $d e^{f} / d e^{h}=d e^{h} / d e^{f}=v_{e}$, where $v_{e}$ is a constant between -1 and 1 . If the home firm forms a conjecture that the foreign firm will increase (decrease) its own net emissions as a result of the home firm raising net emissions, then firms collude (do not collude) i.e., $d e^{f} / d e^{h}=v_{e}>(<) 0$. In the zero-conjecturalvariation case, $v_{e}=0$. A positive (negative) $v_{e}$ implies that the home firm's marginal 
abatement costs increase (decrease), meaning that the extent of a change in its total abatement costs, given a change in home's emissions, is relatively larger (smaller). This is because the home firm's total abatement cost function incorporates the increased (decreased) level of emissions coming from the foreign firm; i.e., $M A C^{h}=-C_{e^{h}}^{h}=$ $\left(1+v_{e}\right)\left(\delta^{h} q^{h}-e^{h}-e^{f}\right) .^{2}$

Remark 2.1. The lower- and upper-bounds for conjectural variation in abatement and output are given, respectively, by $-1<v_{e}<1$ and $-1<v_{q}<1$.

Proof: See appendix A.

Definition 2.2. (i) Conjectural variation in output, $v_{q}$, closer to $1(-1)$ represents the case of relatively more (less) collusion in output. (ii) Conjectural variation in abatement, $v_{e}$, closer to $1(-1)$ represents the case of relatively more (less) collusion in abatement.

The order of events is as follows. The government in each country sets the emission tax in a Cournot-Nash fashion, meaning governments simultaneously choose their own tax taking each other's tax as given so as to maximize welfare. Then, firms take policy as given and choose the level of emissions and output simultaneously. The model is solved via backward induction. We assume interior solutions throughout in order to analyze the role of varying conjectural variations on output and abatement. The assumption of Cournot-Nash in the choice of taxes by governments is made to focus the analysis on the role of conjectural variations at the firm level, with implications, in turn, on the characterization of policy. Furthermore, the assumption about the simultaneous choice of emissions and output by firms is to put aside issues of strategic choice of abatement and output (e.g., Carlsson, 2000; Montero, 2002) and to focus the analysis on the role of conjectural variations.

\section{The equilibrium}

For the home firm, maximization of (1) with respect to $q^{h}$ and $e^{h}$ yields, respectively, the following first-order conditions:

$$
\begin{array}{r}
p^{h}-\beta q^{h}\left(1+v_{q}\right)-c^{h}-\delta^{h}\left(\delta^{h} q^{h}-e^{h}-e^{f}\right)=0 \\
-t^{h}-\left(\delta^{h} q^{h}-e^{h}-e^{f}\right)\left(-1-v_{e}\right)=0,
\end{array}
$$

where $p^{h}=\alpha-\beta\left(q^{h}+q^{f}\right), v_{q}$ in (3) captures the degree of market power associated with conjectural variation in output, and $v_{e}$ in (4) the component of the marginal abatement cost function associated with conjectural variation. Equations (3) and (4), along with an analogous set of equations for the foreign firm, implicitly determine the equilibrium vector $q^{h *}, q^{f *}, e^{h *}$ and $e^{f *}$ as functions of the emission tax $t^{h}, t^{f}$ and conjectural variations parameters $v_{q}, v_{e}$.

\footnotetext{
${ }^{2} v_{e}>0$ captures collusion when firms emit or abate more. Suppose the home firm raises (lowers) emissions and forms a conjecture that the foreign firm will raise (lower) its emissions. Then, the home firm's total abatement costs fall (rise) as a direct increase (decrease) in $e^{h}$, but also indirectly because of the conjectural variation $v_{e}>0$.That is, $M A C^{h} \Rightarrow d T A^{h}=-\left(1+v_{e}\right)\left(\delta^{h} q^{h}-e^{h}-e^{f}\right) d e^{h}$, where $d e^{h}>(<) 0$ when firms emit (abate) more under collusion.
} 
Substitution of (4) into (3), undertaking a similar substitution using the first-order conditions of the foreign firm, and then solving for the equilibrium level of output for the home firm, gives

$$
q^{h}=\frac{\left(\alpha-c^{h}-\left(\delta^{h} t^{h} /\left(1+v_{e}\right)\right)\right)\left(2+v_{q}\right)-\left(\alpha-c^{f}-\left(\delta^{f} t^{f} /\left(1+v_{e}\right)\right)\right)}{\beta\left(\left(2+v_{q}\right)^{2}-1\right)},
$$

where an analogous expression applies to the output level of the foreign firm, $q^{f}$ :

$$
q^{f}=\frac{\left(\alpha-c^{f}-\left(\delta^{f} t^{f} /\left(1+v_{e}\right)\right)\right)\left(2+v_{q}\right)-\left(\alpha-c^{h}-\left(\delta^{h} t^{h} /\left(1+v_{e}\right)\right)\right)}{\beta\left(\left(2+v_{q}\right)^{2}-1\right)} .
$$

Equations (5) and (6) point to the role of conjectural variations in output and abatement in a unified framework. For example, under zero conjecture in abatement $\left(v_{e}=0\right)$, the expression for output still accounts for the role of conjectural variations in output $\left(v_{q} \neq\right.$ 0 ). And with zero conjectural variaton in output and abatement (i.e., $v_{q}=0, v_{e}=0$ ), the Cournot closed-form solution is obtained.

Assumption 3.1. For all $v_{q}$, $v_{e}$ : (i) $\left(\alpha-c^{h}-\delta^{h} t^{h} /\left(1+v_{e}\right)\right)\left(2+v_{q}\right)>\alpha-c^{f}-$ $\delta^{f} t^{f} /\left(1+v_{e}\right)$; (ii) $\quad\left(\alpha-c^{f}-\delta^{f} t^{f} /\left(1+v_{e}\right)\right)\left(2+v_{q}\right)>\alpha-c^{h}-\delta^{h} t^{h} /\left(1+v_{e}\right)$; (iii) $\alpha-c^{k}-\delta^{k} t^{k} /\left(1+v_{e}\right)>0$ for $k=h, f$.

Assumption 3.1 (i), (ii) and (iii) ensure, respectively, positive home output, $q^{h}$, foreign output, $q^{f}$, and aggregate output, $Q=q^{h}+q^{f}$.

\section{Output and conjectural variations}

Using definition 2.2 and equation (5), an increase (decrease) in $v_{q}$ results in lower (higher) home output due to the relatively higher (lower) degree of collusion in output; that is, $\partial q^{h} / \partial v_{q}<0$. Analogous results apply to $q^{f}$. The reason higher $v_{q}$ implies lower output is captured by the term $\left(1+v_{q}\right) \beta q^{h}$ in (3), which indicates the role which the degree of conjectural variation plays in the market power of the home firm.

The analysis with respect to $v_{e}$ indicates that home output may fall or rise; that is, the sign of $\partial q^{h} / \partial v_{e}$ is ambiguous. This is because of two effects. On the one hand, as the conjectural variation $v_{e}$ rises (i.e., starting at any $v_{e}$, a higher degree of collusion in abatement), home's marginal abatement costs increase and, as a result, home raises its own output to equate marginal abatement costs to the existing tax, $t^{h}$. The key element here is the presence of the emission tax which leads to an increase in output. On the other, as the foreign firm also experiences an increase in $v_{e}$ (i.e., by assumption conjectural variation in abatement is identical for the home and foreign firm), foreign also raises its own output to equate its marginal abatement costs to the tax, $t^{f}$. As a result, home reacts strategically by lowering output because of the oligopolistic interaction. If this latter effect is relatively small, then home output rises with a small increase in $v_{e}$. In particular, using (5) gives

$$
\begin{aligned}
\frac{\partial q^{h}}{\partial v_{e}} & =\frac{1}{\left(1+v_{e}\right)^{2}\left(\left(2+v_{q}\right)^{2}-1\right) \beta}\left[\delta^{h} t^{h}\left(2+v_{q}\right)-\delta^{f} t^{f}\right]>0 \\
& \Leftrightarrow \delta^{f} t^{f}<\delta^{h} t^{h}\left(2+v_{q}\right),
\end{aligned}
$$



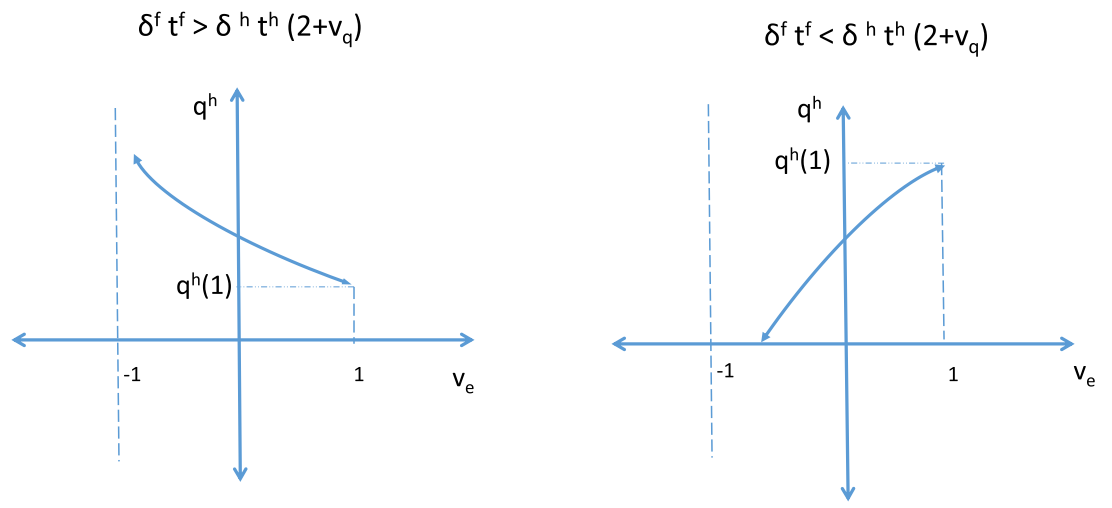

Figure 1. Home output, $q^{h}$, and conjectural variation in abatement, $v_{e}$.

where $\delta^{h} t^{h}\left(2+v_{q}\right)$ denotes the home output-increasing effect, and $-\delta^{f} t^{f}$ the home output-reducing effect as a result of the oligopolistic interaction. Figure 1 illustrates these results, where the right-hand-side and left-hand-side planes illustrate, respectively, that the home output-increasing and output-decreasing effect dominates. An analogous result applies to the foreign country, where using (6) gives: $\partial q^{f} / \partial v_{e}=\left(\delta^{f} t^{f}\left(2+v_{q}\right)-\right.$ $\left.\delta^{h} t^{h}\right) /\left(\left(1+v_{e}\right)^{2}\left(\left(2+v_{q}\right)^{2}-1\right) \beta\right)$. The key mechanism in explaining the sign of $(7)$ is the presence of an emission tax, where an increase in marginal abatement costs (due to an increase in $v_{e}$ ) results in higher emissions and output as the home firm ensures that the existing tax is equal to marginal abatement costs. In section 5 we delve into the implications on abatement and aggregate emissions. Next, we consider aggregate output, $Q=$ $q^{h}+q^{f}=\left(\left(\alpha-c^{h}-\delta^{h} t^{h} /\left(1+v_{e}\right)\right)+\left(\alpha-c^{f}-\delta^{f} t^{f} /\left(1+v_{e}\right)\right)\right) / \beta\left(3+v_{q}\right)$, where it can be shown that output: (i) falls with an increase in $v_{q}$ (i.e., $\partial Q / \partial v_{q}<0$ ); and (ii) rises with an increase in $v_{e}$ (i.e., $\partial Q / \partial v_{e}>0$ ). The intuition for (i) is due to the higher degree of collusion. And the intuition for (ii) is that a higher degree of collusion in abatement means that the output-increasing effect is always large enough. The implication here is that in the presence of nonzero conjectural variation in abatement, equilibrium aggregate output could potentially be larger even in the presence of collusion in the output market.

\subsection{Output, taxation and conjectural variations}

Consider the effect of the tax on home output; in particular, differentiation of (5) yields

$$
\frac{\partial q^{h}}{\partial t^{h}}=\frac{\left(-\delta^{h} /\left(1+v_{e}\right)\right)\left(2+v_{q}\right)}{\beta\left(\left(2+v_{q}\right)^{2}-1\right)}<0 \quad \frac{\partial q^{h}}{\partial t^{f}}=\frac{\delta^{f} /\left(1+v_{e}\right)}{\beta\left(\left(2+v_{q}\right)^{2}-1\right)}>0 .
$$

Results are consistent with the literature (e.g., Requate, 2006). First, an increase in the tax in the home (foreign) country renders the home firm relatively less (more) cost competitive and, as a result, home output falls (rises). Second, aggregate output falls with an increase in either the home or foreign tax.

To see the role of $v_{q}$, we note that the expression $\partial q^{h} / \partial t^{h}$ suggests that the effectiveness of an increase in the home tax in reducing home output is lower as the conjectural variation for output, $v_{q}$, increases. This is because, with a higher degree of collusion in 
output, firms enjoy more market power and thus face a demand which is less price sensitive (see appendix B). As a result, it takes a larger tax increase to induce a change in home output. A similar rationale applies to the effect of foreign taxation using the expression $\partial q^{h} / \partial t^{f}$ : a higher degree of collusion in output renders the foreign tax less effective in altering home output. As a result, the effects on home output via the oligopolistic interdependence are smaller, too. These results are illustrated in figure 2, where the expressions in (8) are plotted as a function of $v_{q}$. For instance, the bottom curve in figure 2 illustrates how a higher degree of collusion is associated with a reduction in the extent to which an increase in the home tax decreases home output. These results will be used in subsequent sections to analyze the relationship between emissions and conjectural variations, and characterize optimal policy. Furthermore, from (8) it can be shown that the effectiveness of a change in the tax in altering output is lower with higher $v_{e}$. The reason is that a higher $v_{e}$ results in higher marginal abatement costs. As a result, it takes a larger tax increase to induce additional abatement, which reflects on subsequent adjustments in output. ${ }^{3}$ The analysis thus implies that an increase in $v_{e}$ reduces the ability of the tax to reduce aggregate output.

Proposition 4.1. For any pollution intensities $\delta^{h}, \delta^{f}$, the effectiveness of an increase in the home tax in: (i) decreasing (increasing) per-firm home (foreign) output; and (ii) reducing aggregate output is lower with either an increase in the conjectural variation in output, $v_{q}$, or abatement, $v_{e}$.

Proof: See appendix C.

\section{Emissions and conjectural variations}

Following the analysis in the previous section, changes in aggregate emissions arising from $v_{q}$ work through changes in output, which implies that aggregate emissions fall with an increase in $v_{q}$ (i.e., $\partial E / \partial v_{q}<0$, see appendix D) regardless of any difference in pollution intensities. We expand on the analysis in section 4 and argue that an increase in $v_{e}$ lowers per-firm abatement and raises per-firm emissions in the presence of an emission tax, meaning that aggregate emissions rise as $v_{e}$ increases (i.e., $\partial E / \partial v_{e}>0$, see appendix D).

To see these results, consider marginal abatement costs for the home firm, $M A C^{h}=$ $-C_{e^{h}}^{h}=\left(1+v_{e}\right)\left(\delta^{h} q^{h}-e^{h}-e^{f}\right)$, where differentiation gives

$$
d M A C^{h}=\left(\delta^{h} q^{h}-e^{h}-e^{f}\right) d v_{e}+\left(1+v_{e}\right)\left(\delta^{h} d q^{h}-d e^{h}-d e^{f}\right),
$$

where $\delta^{h} q^{h}-e^{h}-e^{f}>0$ denotes home-firm abatement. Since the tax remains fixed and the home firm equates marginal abatement costs to the tax, we know that $d M A C^{h}=$ 0 , which implies from (9) that abatement for the home firm falls as $v_{e}$ increases; that is, $\left(\delta^{h} d q^{h} / d v_{e}-d e^{h} / d v_{e}-d e^{f} / d v_{e}\right)<0$. The reduction in home abatement and increase in home emissions arises from the fact that an increase in $v_{e}$ raises marginal abatement costs of the home firm, which in the presence of the tax induces the firm to equate

\footnotetext{
${ }^{3}$ For example, $\partial q^{h} / \partial t^{h}$ indicates that with higher marginal abatement cost, an increase in $t^{h}$ induces a relatively small reduction in emissions; this is captured by a smaller term $-\delta^{h} /\left(1+v_{e}\right)$ (in absolute value) due to an increase in $v_{e}$.
} 


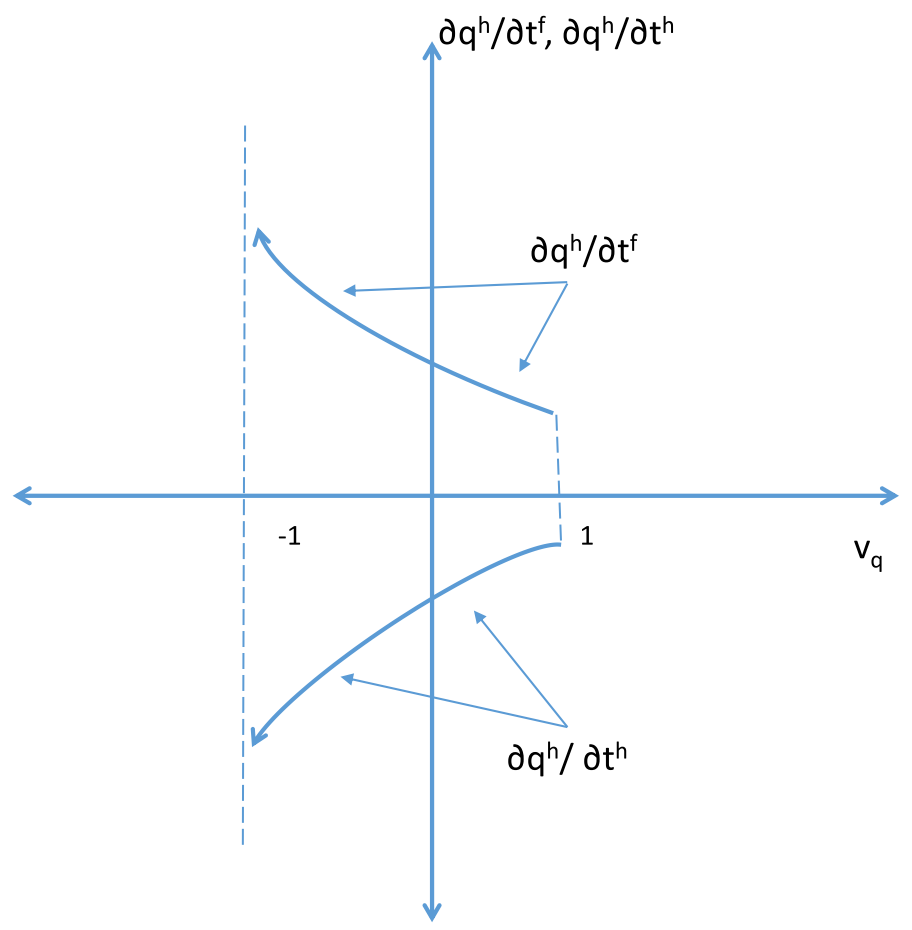

Figure 2. Taxation, home output, $q^{h}$, and conjectural variation, $v_{q}$.

marginal abatement costs to the tax. Since an analogous result applies to the foreign firm, the implication here is that aggregate emissions rise given an increase in $v_{e}$, i.e., $E=e^{h}+e^{f} \Rightarrow \partial E / \partial v_{e}>0$. This result holds regardless of any asymmetries in pollution intensities as home and foreign emissions rise.

Proposition 5.1. For any $\delta^{h}, \delta^{f}$, in the presence of an emission tax, aggregate emissions rise with an increase in the degree of collusion in abatement, $v_{e}\left(i . e ., \partial E / \partial v_{e}>0\right)$.

\subsection{Emissions, taxation and conjectural variations}

We analyze the role of conjectural variation in output on the extent to which the tax is effective in lowering aggregate emissions by considering the change in total emissions with respect to the tax as a function of $v_{q}$. Consider the change in aggregate emissions, $E=e^{h}+e^{f}$, with respect to the tax in the home country (i.e., $\partial E / \partial t^{h}=$ $\left.\partial e^{h} / \partial t^{h}+\partial e^{f} / \partial t^{h}\right)$, where $t^{h} /\left(1+v_{e}\right)=\delta^{h} q^{h}-e^{h}-e^{f}, t^{f} /\left(1+v_{e}\right)=\delta^{f} q^{f}-e^{f}-$ $e^{h}$ from firms' profit-maximization conditions (see appendix $\mathrm{E}$ for a detailed derivation):

$$
\frac{\partial E}{\partial t^{h}}=\frac{1}{1+v_{e}}\left[\delta^{h} \frac{\partial q^{h}}{\partial t^{h}}+\delta f \frac{\partial q^{f}}{\partial t^{h}}-\frac{1}{1+v_{e}}\right],
$$

where the first, second and third terms denote, respectively, changes in aggregate emissions via changes in home output, foreign output and abatement induced by the home 
tax. Next, substitution of $\partial q^{h} / \partial t^{h}$ and $\partial q^{f} / \partial t^{h}$ into (10) yields $\partial E / \partial t^{h}$ as a function of $v_{q}$; that is, $f\left(v_{q}\right) \equiv \partial E / \partial t^{h}$ :

$$
f\left(v_{q}\right)=\frac{1}{\beta\left(1+v_{e}\right)^{2}\left(\left(2+v_{q}\right)^{2}-1\right)}\left[\delta^{h}\left(-\delta^{h}\left(2+v_{q}\right)+\delta^{f}\right)-\beta\left(\left(2+v_{q}\right)^{2}-1\right)\right],
$$

where for any $v_{q}, v_{e}$, equation (11) is negative (positive) if $\delta^{h} \geq \delta^{f}\left(\delta^{f}>\delta^{h}\left(2+v_{q}\right)+\right.$ $\left.\left(\beta\left(2+v_{q}\right)^{2}-1\right) / \delta^{h}\right)$. That is, aggregate emissions fall (rise) with an increase in the home tax if the home (foreign) pollution intensity exceeds foreign's (is sufficiently large). This result arises from (5) and the role of asymmetries in pollution intensities. The reason is that the direction (though not the magnitude) in which foreign and home output change with respect to a tax increase is the same regardless of conjectural variations, thereby pointing to the role of asymmetries in pollution intensities.

Definition 5.2. The foreign firm's pollution intensity coefficient, $\delta^{f}$, is referred to as sufficiently large whenever $\delta^{f}>\bar{\delta}^{f} \equiv \delta^{h}\left(2+v_{q}\right)+\beta\left(\left(2+v_{q}\right)^{2}-1\right) / \delta^{h}$. The home firm's pollution intensity exceeds foreign's whenever $\delta^{h}>\delta^{f}$.

Inspection of (11) gives the following proposition.

Proposition 5.3. For any $v_{q}, v_{e}$, aggregate emissions fall (rise) with an increase in the home tax if the home (foreign) pollution intensity exceeds foreign's (is sufficiently large); i.e., $\delta^{h}>\delta^{f}\left(\delta^{f}>\bar{\delta}^{f}\right)$.

Next, the role of $v_{q}$ is examined using (11) through two cases. First, if $\delta^{h} \geq \delta^{f}$, then $f<0, f^{\prime}>0, f^{\prime \prime}<0 .{ }^{4}$ This means that aggregate emissions fall with taxation at home, but the effectiveness of an increase in the tax in reducing aggregate emissions is lower where there is a higher degree of collusion in output. This is because: (i) home's pollution intensity exceeds foreign's so it offsets any increase in emissions coming from foreign output, which takes place via the increase in $t^{h}$; and (ii) the effectiveness of an increase in the tax in reducing emissions is lower due to larger conjectural variations in output (proposition 4.1).

Second, from equation (11) aggregate emissions rise with an increase in the home tax if $\delta^{f}>\bar{\delta}^{f}$ regardless of whether the output market is relatively close to the perfectly competitive or collusion case. But aggregate emissions increase by more given an increase in the home tax, if $\delta^{f}>\bar{\delta}^{f}$ and the output market is relatively close to the perfectly competitive case, since in this case $v_{q}$ is close to -1 , meaning that output is more sensitive to taxation. This result is illustrated in the top curve of figure 3, where for sufficiently large $\delta^{f}$, lower values of $v_{q}$ are associated with higher levels of $f\left(v_{q}\right)$. However, if $\delta^{f}$ is not sufficiently large, then aggregate emissions fall with an increase in the home tax for a range of $v_{q}$ relatively close to collusion. In this case foreign's pollution intensity is not sufficiently large and taxation on foreign output is relatively less effective (see appendix $\mathrm{F}$ for specific range of $\delta^{f}$ ). The bottom curve in figure 3 illustrates this result. Importantly,

\footnotetext{
${ }^{4}$ Formally, $\left.\quad f^{\prime}\left(v_{q}\right)=\delta^{h}\left[\delta^{h}\left(5+4 v_{q}+v_{q}^{2}\right)-2 \delta^{f}\left(2+v_{q}\right)\right)\right] /\left[\beta\left(1+v_{e}\right)^{2}\left(\left(2+v_{q}\right)^{2}-1\right)^{2}\right] ; \quad f^{\prime \prime}\left(v_{q}\right)=$ $\left.2 \delta^{h}\left[-\delta^{h}\left(2+v_{q}\right)\left(6+4 v_{q}+v_{q}^{2}\right)+\delta^{f}\left(5+4 v_{q}+v_{q}^{2}\right)\right)\right] /\left[\beta\left(1+v_{e}\right)^{2}\left(\left(2+v_{q}\right)^{2}-1\right)^{3}\right]$.
} 


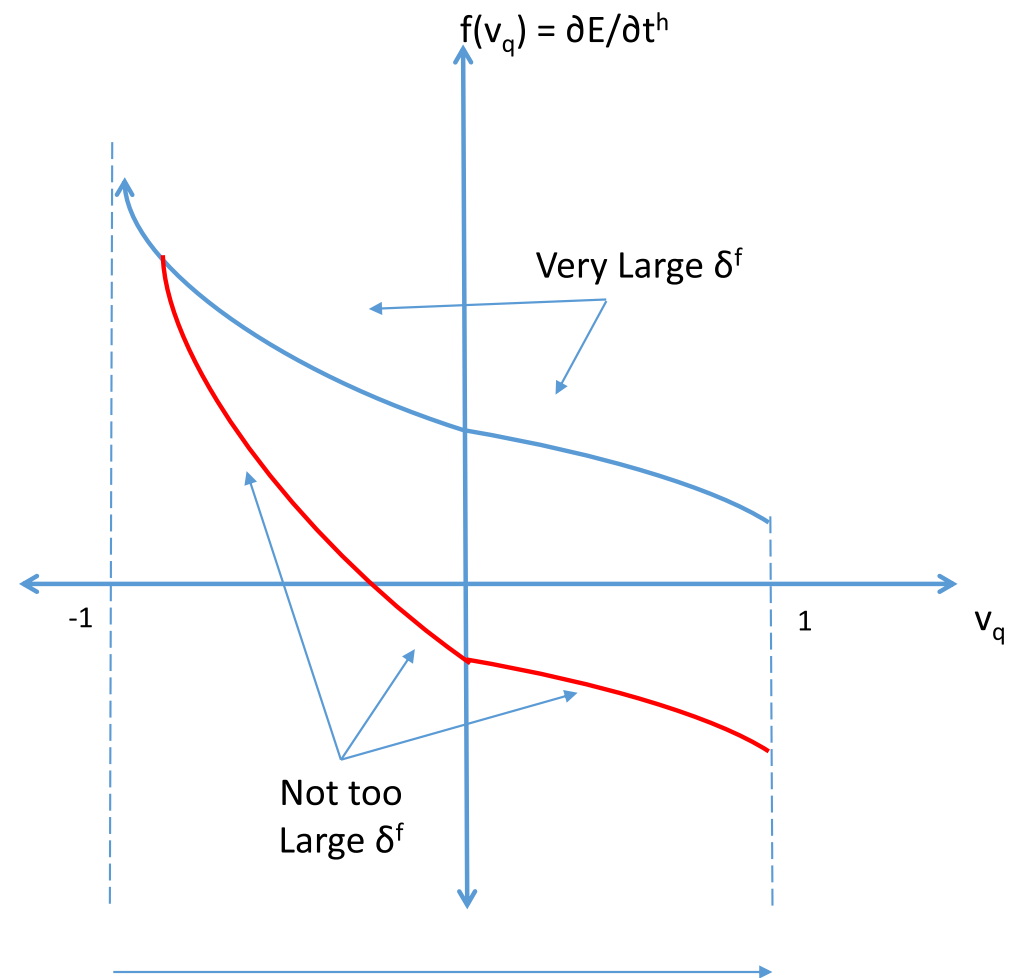

\section{Left to right: away from perfectly competitive market}

Figure 3. Aggregate emissions, $E$, taxation and conjectural variation, $v_{q}$.

results point to the role of pollution intensities coupled with conjectural variation in output, and suggest the need to look for additional measures to tackle emissions, particularly in cases where there is sufficient asymmetry in pollution intensities.

Proposition 5.4. If conjectural variation in output is small and foreign exhibits a sufficiently large pollution intensity, $\delta^{f}>\bar{\delta}^{f}$, then the effectiveness of an increase in the home tax in reducing aggregate emissions is lower.

Proof: See appendix F.

\section{Welfare}

This section looks at the role of conjectural variations in the characterization of the optimal emission tax. The strategy is to first characterize the non-cooperative optimal tax (section 6.1), and then analyze changes in optimal taxation arising from exogenous changes in conjectural variations (sections 6.2 and 6.3). In section 6.2 we show that the non-cooperative tax increases even as output falls with a higher degree of collusion in output (proposition 6.2). The driver is the presence of large asymmetries in pollution intensities, where there are negligible reductions in damages from home emissions (and 
thus little need to lower the tax), but large enough gains from reduced transboundary pollution. A similar analysis is applied to conjectural variation in abatement in section 6.3, where the non-cooperative tax decreases (proposition 6.3) even as emissions rise in markets with a higher degree of collusion in abatement. The reason is that large asymmetries in pollution intensities allow for control of emissions via lower taxation.

\subsection{Non-cooperative tax}

The government in the home and foreign countries set taxes simultaneously via welfare maximization, taking each other's taxes as given.

The home country maximizes the following welfare function:

$$
W^{h}=C S^{h}\left(q^{h}, q^{f}\right)+\pi^{h}+e^{h} t^{h}-\varphi^{h}\left(e^{h}+e^{f}\right),
$$

where $C S^{h}$ denotes consumer surplus, $\pi^{h}$ home profits, $e^{h} t^{h}$ revenue from taxation, and the function $\varphi^{h}(\cdot)$ damages from foreign (transboundary) and home emissions, where $\varphi^{h^{\prime}}>0, \varphi^{h^{\prime \prime}}>0$. It is noteworthy that marginal damages are independent from where the emissions occur. An analogous welfare function applies to the foreign country, $W^{f}$. Differentiation of (12) with respect to $t^{h}$ and, analogously, differentiation of $W^{f}$ with respect to $t^{f}$ yields two first-order conditions (subscripts denote partial derivatives) $W_{t^{h}}^{h}=0$ and $W_{t^{f}}^{f}=0$, and hence a policy vector $t^{h *}, t^{f *}$ as functions of conjectural variations $v_{q}, v_{e}$.

In particular, $W_{t^{h}}^{h}=0$ gives

$$
t^{h *}=\varphi^{h^{\prime}}+\varphi^{h^{\prime}} e_{t^{h}}^{f} / e_{t^{h}}^{h}+q^{f} p_{t^{h}}^{f} / e_{t^{h}}^{h}-\beta\left(1+v_{q}\right) q^{h} q_{t^{h}}^{h} / e_{t^{h}}^{h},
$$

where consistent with the literature (e.g., Lahiri and Symeonidis, 2007; Gautier, 2013) $e_{t^{h}}^{f}>0, e_{t^{h}}^{h}<0, p_{t^{h}}^{f}>0, q_{t^{h}}^{h}<0$ (see derivation of (13) and selected expressions in appendices $G$ and $J$, respectively). The first and second terms denote, respectively, damages from home emissions which put an upward pressure on the home tax, and transboundary pollution which puts a downward pressure because a lower tax at home lowers emissions coming from the foreign firm. The third and fourth terms denote, respectively, profit-shifting, and output distortion effects, each of which puts a downward pressure on the tax. From (13) the home tax is clearly below marginal damages. We assume positive optimal taxation in each country throughout.

\subsection{The non-cooperative tax and conjectural variation, $v_{q}$}

To explore the role of $v_{q}$ on taxation we differentiate the first-order conditions, $W_{t^{h}}^{h}\left(t^{h}\left(v_{q}\right), t^{f}\left(v_{q}\right), v_{q}\right)=0$ and $W_{t^{f}}^{f}\left(t^{h}\left(v_{q}\right), t^{f}\left(v_{q}\right), v_{q}\right)=0$, with respect to $v_{q}$, which yields the change in the home tax given a small change in conjectural variation in output, $t_{v_{q}}^{h}$ :

$$
\eta t_{v_{q}}^{h}=-W_{t^{f} f^{f}}^{f} W_{t^{h} v_{q}}^{h}+W_{t^{h} t^{f}}^{h} W_{t^{f} v_{q}}^{f}
$$

where $\eta=W_{t^{f} t^{f}}^{f} W_{t^{h} t^{h}}^{h}-W_{t^{f} t^{h}}^{f} W_{t^{h} t^{f}}^{h}>0, W_{t^{f} t^{f}}^{f}<0, W_{t^{h} t^{h}}^{h}<0$ by the concavity of the welfare function and stability of the system. The first term in (14) denotes the adjustment in the home tax resulting from welfare changes in that country. And the second 
term captures the adjustment in the home tax as a result of adjustments in the foreign country's tax arising from changes in $v_{q}$. We assume this latter effect is negligible to focus the analysis on firm interdependence. ${ }^{5}$

Assumption 6.1. Cross-country adjustments in the tax are negligible, i.e., $W_{t^{h} t^{f}}^{h} \simeq 0$.

Under assumption 6.1 the expression in equation (14) reduces to

$$
-W_{t^{h} t^{h}}^{h} t_{v_{q}}^{h}=\Omega+\left(t^{h}-\varphi^{h^{\prime}}\right) e_{t^{h} v_{q}}^{h}-\varphi^{h^{\prime}} e_{t^{h} v_{q}}^{f}-\varphi^{h^{\prime \prime}} E_{t^{h}} E_{v_{q}}
$$

where $e_{t^{h} v_{q}}^{h}>0, e_{t^{h} v_{q}}^{f}<0,\left(t^{h}-\varphi^{h^{\prime}}\right)<0, E_{v_{q}}<0$. The sign of $E_{t^{h}}$ (i.e., the change in aggregate emissions from a change in the home tax) is ambiguous as previously discussed and depends on relative pollution intensities. $\Omega$ in (15) denotes consumer surplus, profit and output distortion effects. To focus the analysis on the role of asymmetries in pollution intensities and damages from emissions, we assume these effects to be small. The second term denotes the decrease in the tax since damages from home emissions, $e^{h}$, fall given an increase in $v_{q}$. The third term is positive and captures damages from transboundary pollution. Foreign emissions fall as $v_{q}$ increases and so damages from transboundary pollution decrease, thereby reducing the need for lower taxation. If damages from transboundary pollution had risen, then the home tax would have decreased because a lower tax at home lowers foreign emissions. The sign of the fourth term is ambiguous since it depends on the sign of $E_{t h}$.

To analyze the aforementioned effects and the sign of $t_{v_{q}}^{h}$ in (15), we consider two cases. First, we assume the home firm pollution intensity exceeds foreign's; and second, we assume the foreign firm is relatively pollution intensive.

\subsubsection{Case 1: home exceeds foreign's pollution intensity}

The home firm's pollution intensity exceeds foreign's, $\delta^{h}>\delta^{f}$, and therefore, from section 5, $E_{t^{h}}<0, E_{t^{h} v_{q}}=f^{\prime}>0$. These signs were examined using (11), where $E_{t^{h} v_{q}}$ denotes the extent to which conjectural variation $v_{q}$ affects the effectiveness of an increase in the home tax in reducing aggregate emissions. The focus is on the role of asymmetries in pollution intensities and damages. From (15) the second and third terms are negative and positive, respectively, and on balance negative; i.e., $\left(t^{h}-\varphi^{h^{\prime}}\right) e_{t^{h} v_{q}}^{h}-$ $\varphi^{h^{\prime}} e_{t^{h} v_{q}}^{f}<0$. This is because the effects via home's pollution intensity, and thus damages, are large enough since the home country is relatively more pollution intensive. There are two opposing effects. On the one hand, because damages from home emissions are falling, the home tax falls (i.e., $\left.\left(t^{h}-\varphi^{h^{\prime}}\right) e_{t^{h} v_{q}}^{h}<0\right)$. On the other, as damages from transboundary pollution fall, the need to lower the tax lessens, $-\varphi^{h^{\prime}} e_{t^{h} v_{q}}^{f}>0$. The former effect completely offsets the latter. As for the fourth term, it is negative since aggregate emissions fall with an increase in $v_{q}$ (i.e., $-\varphi^{h^{\prime \prime}} E_{t^{h}} E_{v_{q}}<0$ ), thereby putting a further downward pressure on the tax. Overall, the home tax decreases, viz., $t_{v_{q}}^{h}<0$, because of

\footnotetext{
${ }^{5}$ If marginal damages are assumed to be linear or constant, assumption 6.1 holds given the linearity of the model.
} 
the reduction in damages from emissions. This result is in line with the literature, where lower taxation addresses the output distortion (e.g., Requate, 2006). However, here the decrease in the tax arises from considerations of damages from emissions.

\subsubsection{Case 2: foreign is relatively pollution intensive}

Consider a relatively pollution-intensive foreign firm $\delta^{f}>\hat{\delta}^{f} \equiv 3 \delta^{h}+8 \beta / \delta^{h}$, whence $E_{t^{h} v_{q}}=f^{\prime}<0, E_{t^{h}}>0 .^{6}$ From (15), because foreign is relatively pollution intensive, damages from transboundary pollution dictate the increase in the tax. Specifically, a higher degree of collusion results in lower foreign output, emissions and thus damages from transboundary polllution. This reduces the need to lower the home tax. The fourth term is positive, also reflecting the smaller need to lower the tax. Overall, the home tax increases (i.e., $t_{v_{q}}^{h}>0$ ) because of the larger role reduced damages from transboundary pollution play; i.e., $-\varphi^{h^{\prime}} e_{t^{h} v_{q}}^{f}-\varphi^{h^{\prime \prime}} E_{t^{h}} E_{v_{q}}>-\left(t^{h}-\varphi^{h^{\prime}}\right) e_{t^{h} v_{q}}^{h}$. Equivalently, the reduction in damages from home emissions, and thus the need to decrease taxation, is negligible. This result is important because: (i) it contrasts with the literature (e.g., Ebert, 1992: 158) where taxation falls with larger $v_{q}$ to address the output distortion arising from a higher degree of collusion, and (ii) it underscores the role of asymmetries in pollution intensities in this adjustment. The analysis points to the room governments may have to set taxation in the presence of a relatively high degree of collusion and potentially less competition, but also carbon leakage.

Proposition 6.2. Let the foreign firm be relatively pollution intensive $\left(\delta^{f}>\hat{\delta}^{f}\right)$, and assume small consumer surplus, output distortion and profits effects. Consider an increase in $v_{q}$. The non-cooperative tax in the home country increases if reductions in damages from transboundary pollution are sufficiently large.

Proof: See appendix H.

\subsection{Optimal tax and conjectural variation in abatement, $v_{e}$}

The analysis in this section follows the methodology applied in section 6.2. Results indicate that a higher degree of collusion in abatement results in an increase in the noncooperative home tax if damages from emissions are large enough. This is because, with an increase in $v_{e}$, aggregate emissions rise (i.e., $E_{v_{e}}>0$ ) and so higher taxation is needed. However, if foreign exhibits a sufficiently large pollution intensity, then the home noncooperative tax decreases since a sufficiently large foreign pollution intensity implies that aggregate emissions are controlled with lower taxation (i.e., $E_{t^{h}}>0$ ). This result illustrates the possibility of lower taxation even when there is a higher degree of collusion in abatement and potentially higher emissions. The role of asymmetries in pollution intensities is crucial for this result since it dictates whether a higher/lower tax controls aggregate emissions. But now there is a second effect, absent in section 6.2, which arises from an increase in $v_{e}$. In section 4 , we argue that an increase in $v_{e}$ increases marginal abatement costs, which consequently lowers abatement and the effectiveness of a tax

\footnotetext{
${ }^{6}$ This inequality comes from the analysis of the top curve in figure 3, and is consistent with definition 5.2, where $\delta^{f}>3 \delta^{h}+8 \beta / \delta^{h} \Rightarrow \delta^{f}>\bar{\delta}^{f}=\left(2+v_{q}\right) \delta^{h}+\beta\left(1+v_{q}\right)\left(3+v_{q}\right) / \delta^{h}$ since $v_{q}<1$, where the second inequality is stated in definition 5.2.
} 
increase in reducing aggregate emissions. Analogous to section 6.2 we consider case 1 (case 2) where home (foreign) pollution intensity exceeds foreign's (is sufficiently large).

\subsubsection{Case 1: home exceeds foreign's pollution intensity}

Consider a pollution-intensive home firm $\delta^{h}>\delta^{f}$ where $E_{t^{h}}<0$. Recall $E_{v_{e}}>0$ for any pollution intensity. With these points in mind and using an analogous expression to (14) under assumption 6.1 yields

$$
-W_{t^{h} t^{h}}^{h} t_{v_{e}}^{h}=\hat{\Omega}+t^{h} e_{t^{h} v_{e}}^{h}-\varphi^{h^{\prime}} E_{t^{h} v_{e}}-\varphi^{h^{\prime \prime}} E_{t^{h}} E_{v_{e}} .
$$

$\hat{\Omega}$ in (16) denotes consumer surplus, output distortion and profit effects. As before the focus of the analysis is on the role of pollution intensities and damages, so $\hat{\Omega}$ is assumed small. The term $-\varphi h^{h^{\prime \prime}} E_{t^{h}} E_{v_{e}}>0$ captures the upward pressure on the tax to address rising aggregate emissions. The term $t^{h} e_{t^{h} v_{e}}^{h}$ is also positive. Recall that an increase in $v_{e}$ implies higher abatement costs and thus lower abatement. This consequently puts an upward pressure on the tax to address higher emissions. The term $-\varphi^{h^{\prime}} E_{t^{h} v_{e}}<0$ captures the decrease in the effectiveness of an increase in the home tax to tackle rising aggregate emissions via higher taxation. Overall, (16) suggests that the non-cooperative home tax increases $\left(t_{v_{e}}^{h}>0\right)$, if damages from aggregate emissions are large enough, i.e., $-\varphi^{h^{\prime \prime}} E_{t^{h}} E_{v_{e}}+t^{h} e_{t^{h} v_{e}}^{h}>\varphi^{h^{\prime}} E_{t^{h} v_{e}}$. The reason is that higher taxation addresses higher emissions even in the presence of a less effective tax.

\subsubsection{Case 2: foreign is sufficiently pollution intensive}

Consider a sufficiently large foreign pollution intensity $\delta^{f}>\bar{\delta}^{f}$, where $E_{t^{h}}>0$. Using (16), the non-cooperative home tax decreases $\left(t_{v_{e}}^{h}<0\right)$ if damages from aggregate emissions are large enough. The intuition is that lower home taxation controls rising aggregate emissions (since $E_{t^{h}}>0$ ). The term $-\varphi^{h^{\prime \prime}} E_{t^{h}} E_{v_{e}}<0$ in (16) captures the downward pressure on the tax to address rising aggregate emissions. The term $t^{h} e_{t^{h} v_{e}}^{h}>0$ is positive as explained in section 6.3.1. The term $-\varphi^{h^{\prime}} E_{t^{h} v_{e}}>0$ captures the decrease in the effectiveness in the home tax to tackle rising aggrgeate emissions via lower taxation. Overall, (16) points to a decrease in the non-cooperative home tax $\left(t_{v_{e}}^{h}<0\right)$, if damages from aggregate emissions are large enough, i.e., $t^{h} e_{t^{h} v_{e}}^{h}-\varphi^{h^{\prime}} E_{t^{h} v_{e}}<\varphi^{h^{\prime \prime}} E_{t^{h}} E_{v_{e}}$. This is because lower taxation controls higher emissions even in the presence of a less effective tax.

Proposition 6.3. Let the foreign firm be sufficiently pollution intensive, and assume small consumer surplus, output distortion and profits effects. Consider an increase in $v_{e}$. The non-cooperative tax in the home country decreases if damages from aggregate emissions are sufficiently large.

Proof: See appendix I.

\section{Policy discussion and concluding remarks}

This paper presents a model which incorporates nonzero conjectural variations in abatement and output in a unified framework of analysis. The inclusion of these two elements is relevant to the debate regarding policy design of environmental policy in an international context because they capture potential responses of firms in one country as 
a result of decisions made by its competitors on emissions and production elsewhere. We contribute to the environmental policy literature under oligopoly by deriving cases where optimal taxation may be larger (e.g., relative to the zero-conjectural-variation, Cournot case) due to the presence of nonzero conjectural variations and large asymmetries in pollution intensities. For instance, even in a market with a relatively high degree of collusion, where a lower tax may be prescribed, we show that taxation may be higher in the presence of large asymmetries in pollution intensities. Additionally, for any degree of conjectural variation in output, taxation may be lower even if there is a relatively higher degree of collusion in abatement associated with higher pollution because of large asymmetries in pollution intensities. These results point to the role of asymmetries in pollution intensities across countries and nonzero conjectural variation in the characterization of policy.

In the context of international environmental agreements, negotiating countries may have concerns about issues of carbon leakage and their ability to stay competitive. The analysis suggests that in the presence of leakage, a case can be made for lower taxation in the country where firms are sufficiently less pollution intensive. This is a direct application of proposition 6.3: the presence of large asymmetries in pollution intensities implies that lower taxation by the low-polluting country controls rising aggregate (global) emissions and, at the same time, helps the low-polluting country be more cost competitive. Hoel (1996) also argues that with greater emissions leakage taxes are lower, not because aggregate emissions are controlled via lower taxation, but rather because damages from aggregate emissions are not addressed since taxation simply shifts pollution elsewhere. In our model, in contrast, lower taxation actually helps reduce aggregate emissions via the oligopolistic interdependence of firms. Furthermore, proposition 6.2 suggests that for sufficiently low pollution-intensive countries experiencing increased foreign competition (i.e., a reduction in $v_{q}$ ), a smaller emission tax may be justified in the presence of large damages from transboundary pollution. This reduction in taxation, in the presence of large asymmetries in pollution intensities, addresses concerns about competitiveness and at the same time rising aggregate (global) emissions, particularly damages from transboundary pollution. The key factor behind these results is the presence of large asymmetries in pollution intensities and its implications on emissions via the oligopolistic interdependence.

Specific applications of the results can be illustrated by linking cases (e.g., more/less pollution intensive, more/less foreign competition) to real-life situations and hypothetical scenarios. For instance, a decrease in $v_{q}$ could be interpreted as a newly-signed trade treaty (i.e., output would rise as a result of the treaty) between a high- and low-pollutionintensive country (e.g., Norway and China). In this case the model suggests the possibility of lower taxation by the low-polluting country (in this case, Norway) as long as transboundary pollution damages are large; however, absent large asymmetries in pollution intensities, higher taxation could result. Analogously, if an environmental agreement between a high- and low-pollution-intensive country is broken (increase in $v_{e}$ ), then results suggest that lower taxation by the low-polluting country takes place to control emissions, but also in this case lower taxation addresses concerns about cost competitiveness by the low-polluting country. The exogenous change in $v_{q}$ and $v_{e}$ may help capture effects similar to those from environmental and trade treaties. However, the specific mechanisms causing these changes are not clear in the present model set-up, and so a specific modelling strategy would be required. 
Inevitably, the analysis relies on a set of assumptions which curtails the generality of results, but on the other hand it allows for the derivation of closed-form solutions which in turn facilitate tracing of the equilibrium for a myriad of cases. Additionally, results are derived assuming away the response of the policy adjustment in one country as a result of policy behavior in the other country. Further, the analysis is presented using a two-country model which abstracts from issues of coalitions and the fact that environmental agreements normally entail several countries and not just two. This is a particularly important aspect since one of the key factors driving the results is the presence of large asymmetries in pollution intensities. Similarly, exploring the role of multiple firms within each country could yield interesting results, particularly in the presence of free-entry. We conjecture that the case of fixed number of firms may not yield significantly different results as long as pollution intensities within countries are not heterogenous and the difference in the number of firms across countries is not too large. This is because key in the present analysis is the role of asymmetry of pollution intensities across countries. Another extension is to explore the nature of the marginal abatement cost function so that cases such as substantial learning spillovers (solar panels, electric vehicles) or cross-border invasion (invasive species, diseases) are also captured.

Acknowledgments. I am grateful to an anonymous referee, Prof. E. Somanathan (Co-Editor), and Dimi Xepapadeas (Assistant Editor) for very constructive comments and suggestions.

\section{References}

International Joint Commission Newsletter (2013) More on IJC's Great Lakes Wastewater Treatment Study and Removing Chemicals of Emerging Concern. Available at https://www.ijc.org/en/ more-ijcs-great-lakes-wastewater-treatment-study-and-removing-chemicals-emerging-concern.

Bresnahan T (1981) Duopoly models with consistent conjectures. American Economic Review 71, 934-945.

Carlsson F (2000) Environmental taxation and strategic commitment in duopoly models. Environmental \& Resource Economics 15, 243-256.

Dixit A (1986) Comparative statics for oligopoly. International Economic Review 27, 107-122.

Ebert U (1992) Pigouvian tax and market structure: the case of oligopoly and different abatement technologies. FinanzArchiv / Public Finance Analysis 49, 154-166.

Fang CS, Wang DL, Wang SC, Zhang SN, Qu Z and Wang J (2013) Study on effects of different types of acid rain on nutritional quality of pakchoi. Advanced Material Research 634-638, 122-125.

Figuières C, Jean-Marie A, Quérou N and Tidball M (2004) Theory of Conjectural Variations, vol. 2. Singapore: World Scientific Publishing Co. Pte. Ltd.

Finus M (2003) Stability and design of international environmental agreements: the case of transboundary pollution. In Folmer $\mathrm{H}$ and Tietenberg $\mathrm{T}$ (eds), International Yearbook of Environmental and Resource Economics 2003/4. Cheltenham, UK: Edward Elgar, pp.82-158.

Fujiwara K (2009) Environmental policies in a differentiated oligopoly revisited. Resource and Energy Economics 31, 239-247.

Fung KC (1989) Tariffs, quotas, and international oligopoly. Oxford Economic Papers 41, 749-757.

Gautier L (2013) Multilateral and unilateral policy reform of emission taxes and abatement subsidies in a two-country model with oligopolistic interdependence. Environmental Economics and Policy Studies 15, $59-71$.

Gautier L (2017) Abatement level in environmental agreements when firms are heterogeneous in abatement costs. In Kayalica MÖ, Çağatay S and Mihçi H (eds), Economics of International Environmental Agreements: A Critical Approach. London: Taylor and Francis, pp. 144-164.

Gautier L (2019) The role of multiple pollutants and pollution intensities in the policy reform of taxes and standards. B.E. Journal of Economic Analysis and Policy 19(3), 1-20. https://doi.org/10.1515/ bejeap-2018-0186.

Gelves A and McGinty M (2016) International environmental agreements with consistent conjectures. Journal of Environmental Economics and Management 78, 67-84. 
Hoel M (1996) Should a carbon tax be differentiated across sectors. Journal of Public Economics 59, 17-32.

Hulbert SH (2008) The Salton Sea centennial symposium. Proceedings of a Symposium Celebrating a Century of Symbiosis Among Agriculture, Wildlife and People, 1905-2005, held in San Diego, California, USA, March 2005. Springer.

Kim J and Chang K (1993) An optimal tax/subsidy for output and pollution control under asymmetric information in oligopoly markets. Journal of Regulatory Economics 5, 183-197.

Lahiri S and Symeonidis G (2007) Piecemeal mutilateral policy reforms under asymmetric oligopoly. Journal of Public Economic Theory 9, 885-899.

Lahiri S and Symeonidis G (2017) Environmental protection without loss of international competitiveness. Journal of Public Economic Theory 19(5), 921-936.

Lambertini L (2013) Oligopoly, the Environment and Natural Resources. London: Routledge.

Lee SH (1999) Optimal taxation for polluting oligopolists with endogenous market structure. Journal of Regulatory Economics 15, 293-308.

Lee S and Kim J (1995) Oligopolistic incentives for pollution control with nonzero conjectures. Economics Letters 49, 95-99.

Levin D (1985) Taxation within Cournot oligopoly. Journal of Public Economics 27, 281-290.

Menz FC and Seip HM (2004) Acid rain in Europe and the United States: an update. Environmental Science \& Policy 7, 253-265.

Montero P (2002) Permits, standards, and technology innovation. Journal of Environmental Economics and Management 44, 23-44.

Requate T (2006) Environmental policy under imperfect competition. In Tietenberg T and Folmer H (eds), The International Yearbook of Environmental and Resource Economics 2006/2007. Cheltenham, UK: Edward Elgar Publishing Limited, pp.120-207.

Simpson D (1995) Optimal pollution taxation in a Cournot duopoly. Environmental \& Resource Economics 6, 359-369.

Ulph A (1996) Environmental policy and international trade when governments and producers act strategically. Journal of Environmental Economics and Management 30, 265-281.

Ulph A and Ulph D (2007) Climate change-environmental and technology policies in a strategic context. Environmental \& Resource Economics 37, 159-180.

Zhang F, Cheng M, Sun Z, Wang L, Zhou Q and Huang X (2013) Combined acid rain and lanthanum pollution and its potential ecological risk for nitrogen assimilation in soybean seedling roots. Environmental Pollution 231, 524-532.

\section{Appendices}

\section{A. Bounds for ve and $v_{q}$ (remark 2.1)}

This section derives the lower- and upper-bounds for $v_{e}$ and $v_{q}$ as stated in remark 2.1. We first derive the lower-bounds followed by the upper-bounds.

The lower-bound for $v_{e}$ and $v_{q}$ is -1 . The first-order condition with respect to output, $p^{h}-\beta q^{h}\left(1+v_{q}\right)-c^{h}-\delta^{h}\left(\delta^{h} q^{h}-e^{h}-e^{f}\right)=0$, implies $\beta q^{h}\left(1+v_{q}\right)>0 \Rightarrow v_{q}>$ -1 . This is the lower bound for $v_{q}$. Next, from the first-order condition with respect to emissions, $t^{h} /\left(1+v_{e}\right), v_{e}>-1$ is required to ensure positive marginal abatement costs.

The upper-bound for $v_{e}$ and $v_{q}$ is 1 . This upper-bound captures collusion between the foreign and home firms. Key to obtaining this result of an upper-bound equal to 1 is that the shares are equal and do not change.

Let the shares for home and foreign output be $s^{h}=q^{h} / Q$ and $s^{f}=q^{f} / Q$, where $Q=$ $q^{h}+q^{f}$. Then, differentiation of $s^{h}$ and $s^{f}$ yields $s^{h} d Q+Q d s^{h}=d q^{h}$ and $s^{f} d Q+Q d s^{f}=$ $d q^{f}$. Since shares do not change, $s^{h} d Q=d q^{h}$ and $s^{f} d Q=d q^{f}$. And since shares are identical, $d q^{f} / d q^{h}=v_{q}=1$. An analogous analysis with respect to emissions yields $d e^{f} / d e^{h}=$ $v_{e}=1$.

A few remarks about the upper-bounds are in order. First, consistent with Dixit (1986), different shares gives $d q^{f} / d q^{h}=v_{q}=q^{f} / q^{h}, d e^{f} / d e^{h}=v_{e}=e^{f} / e^{h}$. The analysis does not 
change as long as conjectural variations are constant. Second, the reason for an upperbound of 1 (i.e., $v_{q}<1, v_{e}<1$ ) is to rule out strict equality. The reason is that a value of 1 implies identical cost structures across firms and in such a case the analysis of asymmetries of pollution intensities and marginal abatement costs would be hard to examine.

\section{B. Less price-sensitive demand}

Next, we show that an increase in $v_{q}$ leads to a less price-sensitive demand. In particular, consider the price elasticity of demand:

$$
\frac{Q}{p} \frac{\partial p}{\partial Q}=\frac{Q}{p}(-\beta)=-\beta \frac{Q}{\alpha-\beta Q}=\epsilon<0 .
$$

Then,

$$
\begin{aligned}
\frac{\partial \epsilon}{\partial v_{q}} & =-\beta \frac{\left(p \frac{\partial Q}{\partial v_{q}}-Q \frac{\partial p}{\partial v_{q}}\right)}{p^{2}} \\
& =\frac{-\beta}{p^{2}}\left(p \frac{\partial Q}{\partial v_{q}}+Q \beta \frac{\partial Q}{\partial v_{q}}\right)=\frac{-\beta}{p^{2}} \frac{\partial Q}{\partial v_{q}}(p+Q \beta)=\frac{-\beta}{p^{2}} \alpha \frac{\partial Q}{\partial v_{q}}>0 .
\end{aligned}
$$

Hence, $-\left(\partial \epsilon / \partial v_{q}\right)=\left(\alpha / p^{2}\right)\left(\partial Q / \partial v_{q}\right)<0$.

\section{Proof to proposition 4.1}

Next, we present the proof to proposition 4.1, which consists of parts (i) and (ii), each of which consists of two parts in turn. We show part (i) of the proposition. Let $\partial q^{h} / \partial t^{h}=$ $h\left(v_{q}\right)<0$ and $\partial q^{h} / \partial t^{f}=z\left(v_{q}\right)>0$. First, $h^{\prime}>0, z^{\prime}<0$, where the positive/negative signs imply diminished effectiveness of tax on home/foreign output. It is noteworthy that $v_{q}=-1$ is a vertical asymptote. Second, $\partial^{2} q^{h} / \partial t^{h} \partial v_{e}>0$, and $\partial^{2} q^{f} / \partial t^{h} \partial v_{e}<0$. We now show part (ii). Consider $Q=q^{h}+q^{f}$, where $\partial Q / \partial t^{h}=\partial q^{h} / \partial t^{h}+\partial q^{f} / \partial t^{h}<0$. First, $\partial^{2} Q / \partial t^{h} \partial v_{q}>0$; and second, $\partial^{2} Q / \partial t^{h} \partial v_{e}>0$. The positive sign implies diminished effectiveness of tax.

\section{Expressions for $\partial E / \partial v_{q}, \partial E / \partial v_{e}$}

Next, we derive the expressions for $\partial E / \partial v_{q}, \partial E / \partial v_{e}$. Consider $E=e^{h}+e^{f}$, where

$$
\begin{aligned}
& e^{h}=\delta^{h} q^{h}-\frac{t^{h}}{\left(1+v_{e}\right)}-e^{f} \Rightarrow \frac{\partial e^{h}}{\partial v_{q}}=\delta^{h} \frac{\partial q^{h}}{\partial v_{q}}-v_{e} \frac{\partial e^{h}}{\partial v_{q}} \Rightarrow \frac{\partial e^{h}}{\partial v_{q}}\left(1+v_{e}\right)=\delta^{h} \frac{\partial q^{h}}{\partial v_{q}}<0, \\
& e^{f}=\delta^{f} q^{f}-\frac{t^{f}}{\left(1+v_{e}\right)}-e^{h} \Rightarrow \frac{\partial e^{f}}{\partial v_{q}}=\delta^{f} \frac{\partial q^{f}}{\partial v_{q}}-v_{e} \frac{\partial e^{f}}{\partial v_{q}} \Rightarrow \frac{\partial e^{f}}{\partial v_{q}}\left(1+v_{e}\right)=\delta^{f} \frac{\partial q^{f}}{\partial v_{q}}<0 .
\end{aligned}
$$

Hence,

$$
\frac{\partial E}{\partial v_{q}}=\frac{\partial e^{h}}{\partial v_{q}}+\frac{\partial e^{f}}{\partial v_{q}}=\left(\frac{\delta^{h}}{1+v_{e}} \frac{\partial q^{h}}{\partial v_{q}}\right)+\left(\frac{\delta^{f}}{1+v_{e}} \frac{\partial q^{f}}{\partial v_{q}}\right)<0
$$


Similarly, the expression for $\partial E / \partial v_{e}$ is given by

$$
\begin{aligned}
e^{h} & =\delta^{h} q^{h}-\frac{t^{h}}{\left(1+v_{e}\right)}-e^{f} \Rightarrow \frac{\partial e^{h}}{\partial v_{e}}=\delta^{h} \frac{\partial q^{h}}{\partial v_{e}}+\frac{t^{h}}{\left(1+v_{e}\right)^{2}}-v_{e} \frac{\partial e^{h}}{\partial v_{e}} \Rightarrow \frac{\partial e^{h}}{\partial v_{e}}\left(1+v_{e}\right) \\
& =\delta^{h} \frac{\partial q^{h}}{\partial v_{e}}+\frac{t^{h}}{\left(1+v_{e}\right)^{2}}, \\
e^{f} & =\delta^{f} q^{f}-\frac{t^{f}}{\left(1+v_{e}\right)}-e^{h} \Rightarrow \frac{\partial e^{f}}{\partial v_{e}}=\delta^{f} \frac{\partial q^{f}}{\partial v_{e}}+\frac{t^{f}}{\left(1+v_{e}\right)^{2}}-v_{e} \frac{\partial e^{f}}{\partial v_{e}} \Rightarrow \frac{\partial e^{f}}{\partial v_{e}}\left(1+v_{e}\right) \\
& =\delta^{f} \frac{\partial q^{f}}{\partial v_{e}}+\frac{t^{f}}{\left(1+v_{e}\right)^{2}} .
\end{aligned}
$$

Then, substituting $\partial q^{h} / \partial v_{e}, \partial q^{f} / \partial v_{e}$ and factoring out $\left(1+v_{e}\right)^{2}$ gives

$$
\begin{aligned}
\frac{\partial E}{\partial v_{e}}= & \frac{\partial e^{h}}{\partial v_{e}}+\frac{\partial e^{f}}{\partial v_{e}}=\left(\frac{\delta^{h}}{1+v_{e}} \frac{\partial q^{h}}{\partial v_{e}}+\frac{t^{h}}{\left(1+v_{e}\right)^{2}}\right)+\left(\frac{\delta^{f}}{1+v_{e}} \frac{\partial q^{f}}{\partial v_{e}}+\frac{t^{f}}{\left(1+v_{e}\right)^{2}}\right), \\
= & \frac{1}{\left(1+v_{e}\right)^{2}\left(\left(2+v_{q}\right)^{2}-1\right)}\left(\delta^{h}\left(\delta^{h} t^{h}\left(2+v_{q}\right)-\delta^{f} t^{f}\right)+t^{h}\right. \\
& \left.+\delta^{f}\left(\delta^{f} t^{f}\left(2+v_{q}\right)-\partial t^{h}\right)+t^{f}\right) .
\end{aligned}
$$

\section{E. Derivation of (10)}

Next, we derive the expression in (10). Consider $E=e^{h}+e^{f}$. Then, using the definition of $e^{h}$ and home's first-order condition gives

$$
\begin{aligned}
e^{h} & =\delta^{h} q^{h}-\frac{t^{h}}{\left(1+v_{e}\right)}-e^{f} \Rightarrow \frac{\partial e^{h}}{\partial t^{h}}=\delta^{h} \frac{\partial q^{h}}{\partial t^{h}}-\frac{1}{1+v_{e}}-v_{e} \frac{\partial e^{h}}{\partial t^{h}} \Rightarrow \frac{\partial e^{h}}{\partial t^{h}}\left(1+v_{e}\right) \\
& =\delta^{h} \frac{\partial q^{h}}{\partial t^{h}}-\frac{1}{1+v_{e}} .
\end{aligned}
$$

And similarly, the change in foreign emissions given a change in the home tax is given by

$$
e^{f}=\delta^{f} q^{f}-\frac{t^{f}}{\left(1+v_{e}\right)}-e^{h} \Rightarrow \frac{\partial e^{f}}{\partial t^{h}}=\delta \frac{\partial q^{f}}{\partial t^{h}}-v_{e} \frac{\partial e^{f}}{\partial t^{h}} \Rightarrow \frac{\partial e^{f}}{\partial t^{h}}\left(1+v_{e}\right)=\delta \frac{\partial q^{f}}{\partial t^{h}} .
$$

Hence, the expression in (10) is obtained:

$$
\begin{aligned}
\frac{\partial E}{\partial t^{h}} & =\frac{\partial e^{h}}{\partial t^{h}}+\frac{\partial e^{f}}{\partial t^{h}} \\
\frac{\partial E}{\partial t^{h}} & =\frac{1}{1+v_{e}}\left(\delta^{h} \frac{\partial q^{h}}{\partial t^{h}}-\frac{1}{1+v_{e}}\right)+\frac{1}{1+v_{e}}\left(\delta^{f} \frac{\partial q^{f}}{\partial t^{h}}\right) \\
\frac{\partial E}{\partial t^{h}} & =\frac{1}{1+v_{e}}\left(\delta^{h} \frac{\partial q^{h}}{\partial t^{h}}-\frac{1}{1+v_{e}}+\delta^{f} \frac{\partial q^{f}}{\partial t^{h}}\right) .
\end{aligned}
$$




\section{F. Proof of proposition $\mathbf{5 . 4}$}

Consider definition 5.2; definition 5.2 ensures $f\left(v_{q}\right)$ is decreasing everywhere, i.e., $f^{\prime}<0$. Now, consider two cases. In case $1, \delta^{f}$ is assumed to be very large so that $f\left(v_{q}\right)>0$ (top curve in figure 3 ), a condition which comes from $f(1)>0 \Leftrightarrow \delta^{f}>8 \beta / \delta^{h}+3 \delta^{h}$. This condition is consistent with definition 5.2 since $v_{q}<1$. Hence, $f^{\prime}\left(v_{q}\right)<0, f\left(v_{q}\right)>0 \forall v_{q}$. In case $2, \delta^{f}$ is not too large (bottom curve in figure 3 ), a condition which comes from $f(0)<0 \Leftrightarrow \delta^{f}<3 \beta / \delta^{h}+2 \delta^{h}$. This condition is consistent with definition 5.2. The vertical asymptote $v_{q}=-1$ can be verified using equation (11) and definition 5.2. Hence, from cases 1 and 2, as illustrated in figure 3, there is a range of $v_{q}\left(\operatorname{small} v_{q}\right)$ so that the effectiveness of a tax increase to lower emissions diminishes (i.e., a home-tax increase raises emissions).

\section{G. Derivation of (13)}

Next, we derive (13). Differentiation of (12), while keeping in mind the definition of the profit and cost functions, gives

$$
\begin{aligned}
d W^{h} & =-q^{h} d p^{h}-q^{f} d p^{f}+p^{h} d q^{h}-e^{h} d t^{h}-t^{h} d e^{h} \\
& -c^{h} d q^{h}-\left(\delta^{h} q^{h}-e^{h}-e^{f}\right) d\left[\delta^{h} q^{h}-e^{h}-e^{f}\right]+t^{h} d e^{h}+e^{h} d t^{h}-\varphi^{h^{\prime}} d E \\
& =-q^{f} d p^{f}+\left(p^{h}-c^{h}\right) d q^{h}-\left(\frac{t^{h}}{1+v_{e}}\right) d\left[\delta^{h} q^{h}-e^{h}-e^{f}\right]-\varphi^{h^{\prime}} d E \\
d W^{h} & =-q^{f} d p^{f}+\left(p^{h}-c^{h}-\frac{t^{h} \delta^{h}}{1+v_{e}}\right) d q^{h}-\left(\frac{t^{h}}{1+v_{e}}\right)\left[-d e^{h}-d e^{f}\right]-\varphi^{h^{\prime}} d E .
\end{aligned}
$$

Then, using the fact that $v_{e}=d e^{f} / d e^{h}$ and the firm's first-order condition gives

$$
\begin{aligned}
\frac{\partial W^{h}}{\partial t^{h}} & =-q^{f} \frac{\partial p^{f}}{\partial t^{h}}+\left(p^{h}-c^{h}-\frac{t^{h} \delta^{h}}{1+v_{e}}\right) \frac{\partial q^{h}}{\partial t^{h}}+\left(\frac{t^{h}}{1+v_{e}}\right)\left[1+v_{e}\right] \frac{\partial e^{h}}{\partial t^{h}}-\varphi^{h^{\prime}} \frac{\partial E}{\partial t^{h}} \\
& =-q^{f} \frac{\partial p^{f}}{\partial t^{h}}+\beta q^{h}\left(1+v_{q}\right) \frac{\partial q^{h}}{\partial t^{h}}+t^{h} \frac{\partial e^{h}}{\partial t^{h}}-\varphi^{h^{\prime}} \frac{\partial E}{\partial t^{h}}
\end{aligned}
$$

Then, setting $\partial W^{h} / \partial t^{h}=0$, using $\partial E / \partial t^{h}=\partial e^{h} / \partial t^{h}+\partial e^{f} / \partial t^{h}$, and solving for $t^{h}$ gives equation (13).

\section{H. Proof of proposition 6.2}

Assume $\delta^{f}>3 \delta^{h}+8 \beta / \delta^{h}$; this is consistent with definition 5.2 and therefore, $E_{t^{h}}>0$. Assume consumer surplus, output distortion and profit effects are small. Now consider an increase in $v_{q}$. Then, from (15) there are two opposing effects. On the one hand, a reduction in local pollution since $e^{h}$ falls with an increase in $v_{q}$; this has a downward effect on the tax which is captured by the term $\left(t^{h}-\varphi^{h^{\prime}}\right) e_{t^{h} v_{q}}^{h}<0$. On the other, an increase in $v_{q}$ lowers transboundary pollution since $e^{f}$ falls, and thus the need to lower taxation at home; this is captured by the term $-\varphi^{h^{\prime}} e_{t^{h} v_{q}}^{f}>0$ which indicates an upward pressure on the tax. Since 
foreign's pollution intensity is larger than home's, then $t_{v_{q}}^{h}>0$, because $\left(t^{h}-\varphi^{h^{\prime}}\right) e_{t^{h} v_{q}}^{h}-$ $\varphi^{h^{\prime}} e_{t^{h} v_{q}}^{f}>0$.

\section{Proof of proposition 6.3}

Consider $\delta^{f}$ such that definition 5.2 holds, which means that aggregate emissions fall with a home tax decrease. Assume consumer surplus, output distortion and profit effects are small. Now consider an increase in $v_{e}$. We know that an increase in $v_{e}$ raises aggregate emissions. So, if $\delta^{f}$ is large in the sense of definition 5.2 and damages from aggregate emissions are large enough, then the tax is adjusted downwards. Formally using (16) means $0>-\varphi^{h^{\prime}} e_{t^{h} v_{e}}^{h}-\varphi^{h^{\prime \prime}} E_{t^{h}} E_{v_{e}}$ large.

\section{J. Derivation of selected expressions}

Next, various expressions used in the welfare analysis are presented:

$$
\begin{aligned}
& q_{t^{h}}^{h}=\frac{\left(-\delta^{h} /\left(1+v_{e}\right)\right)\left(2+v_{q}\right)}{\beta\left(\left(2+v_{q}\right)^{2}-1\right)}=\frac{-\delta^{h}\left(2+v_{q}\right)}{\beta\left(1+v_{e}\right)\left(1+v_{q}\right)\left(3+v_{q}\right)}<0 ; \\
& q_{t^{h}}^{f}=\frac{\delta^{h} /\left(1+v_{e}\right)}{\beta\left(\left(2+v_{q}\right)^{2}-1\right)}=\frac{\delta^{h}}{\beta\left(1+v_{e}\right)\left(1+v_{q}\right)\left(3+v_{q}\right)}>0 \\
& Q=q^{h}+q^{f} \Rightarrow Q_{t^{h}}=\frac{\left(-\delta^{h} /\left(1+v_{e}\right)\right)\left(2+v_{q}\right)}{\beta\left(\left(2+v_{q}\right)^{2}-1\right)}+\frac{\delta^{h} /\left(1+v_{e}\right)}{\beta\left(\left(2+v_{q}\right)^{2}-1\right)} \\
& =\frac{-\delta^{h}}{\beta\left(1+v_{e}\right)\left(3+v_{q}\right)}<0 \\
& p^{f}=\alpha-\beta\left(q^{h}+q^{f}\right)=\alpha-\beta Q \Rightarrow p_{t^{h}}^{f}=-\beta Q_{t^{h}}>0 ; \\
& Q_{t^{h}}=\frac{-\delta^{h}}{\beta\left(1+v_{e}\right)\left(3+v_{q}\right)}<0 ; \quad Q_{t^{h} v_{q}}=\frac{\delta^{h}}{\beta\left(1+v_{e}\right)\left(3+v_{q}\right)^{2}}>0 ; \quad Q_{t^{h} v_{e}}>0 ; \\
& p_{t^{h} v_{q}}^{f}=-\beta Q_{t^{h} v_{q}}<0 ; \quad p_{t^{h} v_{e}}^{f}=-\beta Q_{t^{h} v_{e}}<0 ; \\
& q_{t^{h} v_{q}}^{h}=\frac{\delta^{h}\left(5+4 v_{q}\right)}{\beta\left(1+v_{e}\right)\left(1+v_{q}\right)^{2}\left(3+v_{q}\right)^{2}}>0 \\
& q_{t^{h} v_{q}}^{f}=\frac{-\delta^{h} 2\left(2+v_{q}\right)}{\beta\left(1+v_{e}\right)\left(1+v_{q}\right)^{2}\left(3+v_{q}\right)^{2}}<0 ; \\
& e_{t^{h}}^{h}=\delta^{h} q_{t^{h}}^{h}-\frac{1}{1+v_{e}}-v_{e} e_{t^{h}}^{h} \Rightarrow e_{t^{h}}^{h}=\frac{1}{1+v_{e}}\left(\delta^{h} q_{t^{h}}^{h}-\frac{1}{1+v_{e}}\right)<0 ; \\
& e_{t^{h} v_{q}}^{h}=\frac{1}{1+v_{e}}\left(\delta^{h} q_{t^{h} v_{q}}^{h}\right)>0 ; \quad e_{t^{h} v_{e}}^{h}=\frac{2}{\left(1+v_{e}\right)^{3}}\left(\frac{\delta^{h 2}\left(2+v_{q}\right)}{\beta\left(\left(2+v_{q}\right)^{2}-1\right)}+1\right)>0 \text {; }
\end{aligned}
$$




$$
\begin{gathered}
e_{t^{h}}^{f}=\delta^{f} q_{t^{h}}^{f}-v_{e} e_{t^{h}}^{f} \Rightarrow e_{t^{h}}^{f}=\frac{1}{1+v_{e}}\left(\delta^{f} q_{t^{h}}^{f}\right)>0 ; \\
e_{t^{h} v_{q}}^{f}=\frac{1}{1+v_{e}}\left(\delta^{f} q_{t^{h} v_{q}}^{f}\right)<0 ; \quad e_{t^{h} v_{e}}^{f}=-\delta^{f} q_{t^{h}}^{f} /\left(1+v_{e}\right)^{2}+\delta^{f} q_{t^{h} v_{e}}^{f} /\left(1+v_{e}\right)<0 \\
q_{t^{h} v_{e}}^{f}=-\delta^{h} / \beta\left(1+v_{e}\right)^{2}\left(\left(2+v_{q}\right)^{2}-1\right)<0 ; \quad E_{t^{h} v_{e}}=e_{t^{h} v_{e}}^{h}+e_{t^{h} v_{e}}^{f} \\
=\frac{\left.\delta^{h 2}\left(2+v_{q}\right)-\delta^{h} \delta^{f}+\beta\left(\left(2+v_{q}\right)^{2}-1\right)\right)}{\left.\beta\left(1+v_{e}\right)^{3}\left(\left(2+v_{q}\right)^{2}-1\right)\right)} ; \\
\Omega=-\left(q^{f} p_{t^{h} v_{q}}^{f}+q_{v_{q}}^{f} p_{t^{h}}^{f}\right)+\beta\left(1+v_{q}\right)\left(q^{h} q_{t^{h} v_{q}}^{h}+q_{t^{h}}^{h} q_{v_{q}}^{h}\right)+\beta q^{h} q_{t^{h}}^{h} ; \\
\hat{\Omega}=-\left(q^{f} p_{t^{h} v_{e}}^{f}+q_{v_{e}}^{f} p_{t^{h}}^{f}\right)+\beta\left(1+v_{q}\right)\left(q^{h} q_{t^{h} v_{e}}^{h}+q_{t^{h}}^{h} q_{v_{e}}^{h}\right) .
\end{gathered}
$$

Cite this article: Gautier L (2022). The role of nonzero conjectural variation in pollution abatement and output in the design of emission taxes. Environment and Development Economics 27, 184-207. https://doi. org/10.1017/S1355770X21000127 